\title{
Influence of chemical speciation on the separation of metal ions from chelating agents by nanofiltration membranes
}

T. Balanyà, J. Labanda, J. Llorens, and J. Sabaté

\section{QUERY SHEET}

This page lists questions we have about your paper. The numbers displayed at left can be found in the text of the paper for reference. In addition, please review your paper as a whole for correctness.

Q1: $\quad$ Au: Please supply full names for all authors as this is required by journal style.

Q2: $\quad$ Au: Corresponding author givenname mismatch with CATS.

Q3: $\quad \mathrm{Au}$ : References [Coman et al., 2013; Kurniawan et al., 2006; Favre-Réguillon et al., 2007; Poriel et al., 2006; Koseoglu and Kitis, 2009; Balanyà et al., 2009; Sabaté et al., 2009; Cavaco Morão et al., 2008; Bandini and Vezzani, 2003; Lefebvre, 2003; Saliha et al., 2009; Pages et al., 2013; Saçmaci et al., 2011; Yaroshchuk, 2008; Dermont et al., 2008; Helgeson and Kirkham, 1974; Helgeson and Kirkham, 1974; Helgeson and Kirkham, 1976; Helgeson et al., 1981; Bardot et al., 1995; Coman et al., 2003; Liu et al., 2008; Ku et al., 2005; Wu, 2016; Suárez et al., 2013; Diallo et al., 2013; Lin et al., 2005; Sorin, 2005] have been updated. OK?

Q4: $\quad$ Au: Please provide missing journal title for the [14] references list entry.

Q5: $\quad$ Au: Please provide missing journal title for the [26] references list entry.

Q6: Au: Please provide missing journal title for the [28] references list entry.

\section{TABLE OF CONTENTS LISTING}

The table of contents for the journal will list your paper exactly as it appears below:

Influence of chemical speciation on the separation of metal ions from chelating agents by nanofiltration membranes T. Balanyà, J. Labanda, J. Llorens, and J. Sabaté 


\title{
Influence of chemical speciation on the separation of metal ions from chelating agents by nanofiltration membranes
}

\author{
T. Balanyàa, J. Labanda ${ }^{b}$, J. Llorens ${ }^{b}$, and J. Sabatéa \\ aDepartament d'Enginyeria Agroalimentària i Biotecnologia, Universitat Politècnica de Catalunya, Castelldefels, Spain; ${ }^{\text {b}}$ Departament \\ 5 d'Enginyeria Química, Universitat de Barcelona, Barcelona, Spain
}

\section{ABSTRACT}

The simultaneous separation of various metal ions (nickel, copper, calcium, and iron) from chelating agents (EDTA and citric acid in water streams using Nanofiltration membranes is analyzed. Assuming that multiply-charged species are highly rejected, chemical speciation computations reproduce the observed patterns of metal and ligand rejection at different $\mathrm{pH}$ values and concentrations. The separation of metal ions from citric acid is achieved in acidic conditions, where multiply-charged free metal ions and neutral or singly charged free chelating species are abundant. Overall, speciation studies help to evaluate the applicability of Nanofiltration for recycling chelating agents used for metal extraction.

\section{ARTICLE HISTORY}

Received 15 November 2017

Accepted 17 July 2018

\section{KEYWORDS}

Nanofiltration; metal; chelate; speciation agents must be separated from the metal ions for their

\section{Introduction}

Several techniques that include precipitation, adsorption, ion-exchange, electrochemical treatments, and membrane filtration have been proposed to separate or concentrate heavy metals from contaminated waters produced by several industries. ${ }^{[1-5]}$ Among them, Nanofiltration is a membrane process that show high retention of multiply-charged ions but their efficiency is influenced by factors such as other ions (e.g., sodium, calcium, iron, sulfate, nitrate, and chloride), $\mathrm{pH}$, and ionic strength. ${ }^{[6,7]}$ Further, some water streams contain chelating agents because they are used to prevent the formation of insoluble salts incrustations or to extract metal ions from liquid streams or from solids such as contaminated soil, sludge, and sediment.

Nanofiltration of solutions containing metal ions such as $\mathrm{Cu}, \mathrm{Ni}, \mathrm{Mn}, \mathrm{Sr}, \mathrm{Co}$, rare earth elements, and radionuclides in the presence of various complexing agents (e.g., EDTA, NTA, DTPA, citric acid, $\mathrm{NH}_{3}, \mathrm{CN}^{-}$, and phosphates) using membranes with different molecular weight cut-off (MWCO) values (i.e., 150-1000 Da) has been studied by several authors. ${ }^{[-16]}$ Most of them reported that the addition of a chelating agent increases metal rejection because the chelate species is larger than the free metal ions. Consequently, metal rejection rises as the $\mathrm{pH}$ increases due to complexation between the metals and the chelating agent. Clearly, the chelating recovery. This process involves fragmentation of the complex, which can be achieved at low $\mathrm{pH}$. Additionally, Nanofiltration membranes must facilitate very distinct rejection for metal ions and ligands. Most of the aforementioned studies investigated only metal ion rejection, and little attention was given to the rejection of chelating agents.

In a previous work, ${ }^{[17]}$ the present authors examined the separation of copper ions from citric acid in synthetic solutions using several Nanofiltration membranes of different pore size and nature. Membranes with narrow pore sizes (e.g., SelRO $尺$ MPF-34, Koch) simultaneously rejected both the copper ions and citrate. However, both species leaked through a ceramic membrane with larger pores (i.e., CERAM INSIDE $®$, Tami). Using a SelRO $尺$; MPF-36 (Koch) at $\mathrm{pH} \approx 2, \mathrm{Cu}^{2+}$ and citric acid experienced high and low rejection, respectively, even though they have similar radius: $0.365^{[18]}$ and $0.344 \mathrm{~nm},{ }^{[19]}$ respectively. According to the manufacturer, ${ }^{[20]}$ this membrane has a MWCO of $1000 \mathrm{Da}$, an estimated mean pore radius of $0.86 \mathrm{~nm},{ }^{[21]}$ an isoelectric point (IEP) of $\sim 5-6,{ }^{[21]}$ and is positively charged at $\mathrm{pH} \approx 2$. Our previous results were understood in terms of the more prominent role played by the electrostatic and dielectric interactions, rather than steric hindrance, between this membrane and the solutes. It would be interesting to extend this study to solutions that contain several different metals and test other chelating agents. 
Indeed, understanding the mechanisms that control the Nanofiltration process can be helpful to increase the predictive capability and improve the efficiency of these separations. The most reported mechanistic model in this regard is the Donnan, Steric and Dielectric Exclusion Pore Model (DSDE-PM), which assumes that Nanofiltration membranes are porous and can maintain an electrical charge. ${ }^{[22-26]}$ Further, the DSDE-PM considers that Steric Hindrance, Donnan Equilibrium, and Dielectric Exclusion determine the partitioning of solutes between the solutions and membrane surfaces, ${ }^{[27]}$ and that the extended Nernst-Planck equation, which considers diffusion, convection, and electro-migration of solutes, governs the transport across the membrane. ${ }^{[28]}$

Multi-ionic solutions are a more accurate representation of real streams, and their Nanofiltration study and modeling has yielded some notable findings. ${ }^{[21,23,26,29-33]}$

90 On the one hand, theoretical models explained that the presence of a multiply-charged ion, which is strongly expelled from the membrane by dielectric exclusion, increases the concentration of singly charged ions of the same sign in the membrane in order to fulfill electroneutrality and the Donnan potential. Thus, the rejection of singly charged ions diminishes, and in some cases can reach a negative value. The energy required to pump these singly charged ions through the membrane interface is provided by the Donnan potential, which is generated by the strongly expelled multiply-charged ions. On the other hand, the presence of very mobile ions, such as $\mathrm{H}^{+}$, reduces the electromigration of other cations and augments their rejection. ${ }^{[21,34]}$ Further, the models also predict a surprising feature of ions with an electrical charge opposite to the membrane: smaller counterions (with high mobility) are rejected more than larger counterions (with low mobility) with the same charge as long as the steric factor is low. ${ }^{[21,34]}$ This feature can enhance the separation of heavy metals and chelating agents at low $\mathrm{pH}$ where some Nanofiltration membranes exhibit positive electrical charge; the presence of an anion, such as $\mathrm{Cl}^{-}$ from $\mathrm{HCl}$ added to achieve low $\mathrm{pH}$, should reduce the rejection of the larger and less mobile counterions, such as some singly charged chelating anions.

The main objective of the present study is to investigate the simultaneous separation of several metal ions from chelating agents by Nanofiltration membranes. Further, we calculate the speciation of the solutions to filter and test its capability to explain the tendencies of the observed rejections. The target synthetic solutions contain two heavy metals (nickel and copper) and either calcium or iron. This ion mixture could occur in the extract of a contaminated soil. We choose two

common extracting agents (i.e., EDTA and citric acid) that form chelates with very different stabilities and determine the performance of their separation and recycling ability. We filter solutions that contain several metals together because multi-solutes solutions are closer to real streams, they allow one to observe and analyze the interactions and competitions between metals and it is a way to assess the conclusions raised from single metal experiments.

\section{Experimental}

\section{Chemicals and analysis}

All of the reagents (i.e., metal chloride salts, citric acid, $\mathrm{NaOH}, \mathrm{HCl}$, glucose, and $\mathrm{Na}_{2} \mathrm{EDTA}$ ) were purchased as pure grade from PanReac (Castellar del Vallès, Barcelona, Spain) and used as received. Pure water was prepared by filtering water through a Milli-Q (Millipore, Burlington, MA, USA) water purification system with a $45 \mu \mathrm{m}$ pore diameter membrane. Copper, nickel, and iron were determined by atomic absorption spectroscopy (SpectrAA110, Varian, Santa Clara, CA, USA), calcium by capillary electrophoresis (3D-CE, Hewlett-Packard, Palo Alto, CA, USA), and glucose, EDTA, and citric acid by total organic carbon analysis (TOC-VSCN, Shimadzu, Kyoto, Japan). A pH meter (Crison Instruments, Barcelona, Spain) was used for the $\mathrm{pH}$ measurements.

\section{Membranes and nanofiltration device}

The experimental instrumentation used herein has been described elsewhere. ${ }^{[21]}$ Flat organic membranes

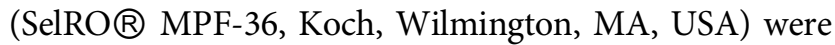
used in all experiments; according to the manufacturer, these membranes have a MWCO of $1000 \mathrm{Da}$, a permeability of $1.6010^{-3} \mathrm{~L} \mathrm{~m}^{-2} \mathrm{~s}^{-1} \mathrm{bar}^{-1}$, a glucose rejection between 0.3 and 0.5 , and an operation range between $\mathrm{pH}$ 1 and $\mathrm{pH} 13 .{ }^{[20]}$ Membranes were fitted in a membrane element cell (SEPA CF II, Osmonics, Minnetonka, MN, USA). The total filtration area was $140 \mathrm{~cm}^{2}$. The retentate stream circulated tangentially to the membrane. A previous study ${ }^{[17]}$ indicated that increasing transmembrane pressure and therefore the flow rate favors the copper retention. Then a high value of transmembrane pressure (14 bar) was selected. The cross-flow velocity was high $\left(1 \mathrm{~m} \mathrm{~s}^{-1}\right)$ to reduce the concentration polarization layer.${ }^{[21]}$ The temperature was maintained at $25 \pm 0.5^{\circ} \mathrm{C}$.

The experimental device consisted of a reservoir tank, a pump, a closed-pipe pressure dampener to prevent pressure oscillation, pressure gauges, a filtration cell, and flow meters for the retentate and permeate. 135 


\section{Filtration runs}

First, the system was filled and run with pure water. To check the state of the membrane, the membrane permeability, $L_{p}$, was calculated as the ratio between the permeate flow and the transmembrane pressure. Specific quantities of solutes and water were added to obtain the prescribed concentrations. The initial feed volume was $5 \mathrm{~L}$. Both the permeate and retentate were returned to the stirred feed tank for the steady-state experiments, while only the retentate was returned for the batch runs. The feed $\mathrm{pH}$ was established by adding $\mathrm{HCl}$ solution dropwise and was continuously measured. After $1 \mathrm{~h}$ of establishing the experimental conditions, which is sufficient to achieve steady state, the permeate and retentate were sampled and diluted for analysis. Between the runs, the membranes were cleaned in situ with pure water, then with $\mathrm{HCl}$ or $\mathrm{NaOH}$ solutions, and then again with pure water.

\section{Experimental design}

190 To analyze the effects of the heavy metal concentrations, the ligand to metal ratio and the stability of chelates evolved we designed experiments to assess the separation of $\mathrm{Ni}^{2+}, \mathrm{Cu}^{2+}, \mathrm{Ca}^{2+}$, and $\mathrm{Fe}^{3+}$ from two ligands (Table 1). $\mathrm{Ni}^{2+}$ and $\mathrm{Cu}^{2+}$ are two heavy metals; $\mathrm{Fe}^{3+}$ is a trivalent ion that forms very stable chelates; and $\mathrm{Ca}^{2+}$ possesses a relatively low tendency for complexation. Moreover, both $\mathrm{Fe}^{3+}$ and $\mathrm{Ca}^{2+}$ are usually present in soils and interfere in heavy metal extraction. ${ }^{[35]}$ In these experiments, we prepared mixtures of several metals together with each chelating agent and filtered them at different $\mathrm{pH}$ values, which were obtained by adding $\mathrm{HCl}$.

All experiments except \#2 were performed with membranes from the same batch, which had a permeability of $3.0 \times 10^{-3} \mathrm{~L} \mathrm{~m}^{-2} \mathrm{~s}^{-1} \mathrm{bar}^{-1}$ and a glucose rejection of pores; its permeability was $1.90 \times 10^{-3} \mathrm{~L} \mathrm{~m}^{-2} \mathrm{~s}^{-1} \mathrm{bar}^{-1}$ and its glucose rejection was 0.44 .

\section{Computation of speciation}

When metals and chelating agents are mixed the resulting solution contains a wide variety of species with distinct electrical charges and molecular sizes that contribute to the equilibria of several chemical reactions. The chemical speciation of the retentate was calculated using OLI Studio. ${ }^{[36]}$ This software takes equilibrium constants $\left(K_{a}\right.$, $\mathrm{K}_{\mathrm{ps}}$, stability constants of complexes) and redox potentials compiled from literature and it theoretically predicts the thermodynamic behavior of aqueous electrolytes using the HKF (Helgeson-Kirkham-Flowers) model. ${ }^{[37-40]}$ It considers activity coefficients and therefore it makes rigorous computations in a wide range of ionic strength. Table 2 shows the relevant stability constants of the chelates. ${ }^{[41]}$ Clearly, chelates with EDTA ${ }^{4-}$ are more stable than those with citrate $\left(\mathrm{Cit}^{3-}\right)$, and the preferences of both chelating agents for the target metals follow the sequence: $\mathrm{Fe}^{3+}>\mathrm{Cu}^{2+} \approx \mathrm{Ni}^{2+}>\mathrm{Ca}^{2+}$.

Partially protonated species of both EDTA and citric acid can also bind metal ions, but their affinities are not as strong as those of the completely ionized species. The successive $\mathrm{pKa}$ values for citric acid $\left(\mathrm{H}_{3} \mathrm{Cit}\right)$ are 3.13, 4.76, and 6.40; the analogous values for EDTA $\left(\mathrm{H}_{6} \mathrm{EDTA}^{2+}\right)$ are $0.98,1.48,2.17,3.12,6.80$, and 11.34 .

The software inputs were $\mathrm{pH}$ and solutes concentrations: metal salts and ligands. The concentrations of the different species present in the retentate solution were calculated. It includes the following species: $\mathrm{Cl}^{-}, \mathrm{Na}^{+}$,

Table 2. Stability constants $\left(\log _{10} \beta_{1}\right)$ of metal-ligand complexes at $20^{\circ} \mathrm{C}^{[37]}$.

\begin{tabular}{lllll}
\hline & \multicolumn{4}{c}{$\log _{10} \beta_{1}$} \\
\cline { 2 - 5 } & $\mathrm{Ca}^{2+}$ & $\mathrm{Ni}^{2+}$ & $\mathrm{Cu}^{2+}$ & $\mathrm{Fe}^{3+}$ \\
\hline EDTA $^{4-}$ & $11.00^{1}$ & $18.62^{1}$ & $18.92^{1}$ & $23.75^{2}$ \\
$\mathrm{HEDTA}^{3-}$ & $3.51^{1}$ & $11.56^{1}$ & $11.54^{1}$ & $14.59^{2}$ \\
$\mathrm{Cit}^{3-}$ & $3.40^{2}$ & $5.40^{2}$ & $8.10^{2}$ & $11.40^{2}$ \\
$\mathrm{HCit}^{2-}$ & $2.10^{2}$ & $3.30^{2}$ & $3.42^{2}$ & - \\
$\mathrm{H}_{2} \mathrm{Cit}^{-}$ & $1.05^{2}$ & $1.75^{2}$ & $2.26^{2}$ & - \\
\hline
\end{tabular}

${ }^{1}$ in $0.1 \mathrm{M} \mathrm{KNO}_{3}{ }^{2}$ in $0.1 \mathrm{M} \mathrm{NaClO}_{4}$. differed slightly than expected from the manufacturer's description (i.e., $1.60 \times 10^{-3} \mathrm{~L} \mathrm{~m}^{-2} \mathrm{~s}^{-1} \mathrm{bar}^{-1}$ and a glucose rejection between 0.3 and 0.5$).{ }^{[20]}$ The membrane used in experiment $\# 2$ came from another batch and had narrower

Table 1. Separation experiments.

\begin{tabular}{lcllcc}
\hline Mode & Reference & \multicolumn{1}{c}{ Metals } & Chelating & $\begin{array}{c}\text { Metal conc. } \\
(\mathrm{mM})\end{array}$ & Chelating conc. (mM) \\
\hline SS & $1 \mathrm{a}$ & $\mathrm{Ca}^{2+} \mathrm{Cu}^{2+} \mathrm{Ni}^{2+}$ & - & 0.1 & - \\
SS & $1 \mathrm{~b}$ & $\mathrm{Fe}^{3+}$ & - & 0.1 & - \\
$\mathrm{SS}$ & 2 & $\mathrm{Ca}^{2+} \mathrm{Cu}^{2+} \mathrm{Ni}^{2+}$ & EDTA & 1.0 & 3.0 \\
SS & 3 & $\mathrm{Fe}^{3+} \mathrm{Cu}^{2+} \mathrm{Ni}^{2+}$ & EDTA & 0.1 & 0.3 \\
SS & 4 & $\mathrm{Ca}^{2+} \mathrm{Cu}^{2+} \mathrm{Ni}^{2+}$ & Citric acid & 1.0 & 3.0 \\
SS & 5 & $\mathrm{Fe}^{3+} \mathrm{Cu}^{2+} \mathrm{Ni}^{2+}$ & Citric acid & 0.1 & 0.3 \\
SS & 6 & $\mathrm{Fe}^{3+} \mathrm{Cu}^{2+} \mathrm{Ni}^{2+}$ & Citric acid & 0.1 & 1.5 \\
Batch & 7 & $\mathrm{Fe}^{3+} \mathrm{Cu}^{2+} \mathrm{Ni}^{2+}$ & Citric acid & 0.1 & 1.5 \\
\hline
\end{tabular}


$\mathrm{H}^{+}, \mathrm{OH}^{-}$, free metal ions, free ligands (EDTA or citric), metal chelates, metal hydroxide and chloride complexes and even though some polynuclear metal chelates that are marginal. All species containing metal atoms can affect metal rejection on account of their complexes charge, which may differ from those of the free metal ions.

Given the multifaceted chemical speciation of the solutions studied herein, the calculations attempt to explain the tendencies of the metal and chelating agent rejections rather than make accurate predictions about specific experiments. For each metal and ligand, the fraction of multiply-charges species (X) is calculated as:

$$
X=\frac{\sum C_{\text {multiply-charged species }}}{\sum C_{\text {all species }}}
$$

where $C$ is the species concentration in the solution to be filtered.

\section{Results and discussion}

Performance of analysis methods were checked along the experiments. The range of calibration samples $\left(\mathrm{mg} \mathrm{L}^{-1}\right)$ was $0.5-5.0$ for copper, nickel and iron, 5-50 for calcium and 10-200 for TOC. For all cases $\mathrm{R}^{2}>0.998$. The limits of detection (LOD), corresponding to three times the standard deviation of the water sample analysis ( $3 \mathrm{~s}$ ), were $\left(\mathrm{mg} \mathrm{L}^{-1}\right), 0.007,0.009,0.007,0.6$ and 0.4 for copper, nickel, iron, calcium and TOC, respectively. Relative standard deviation (RSD) of the analysis methods were determined from duplicates analysis of permeate samples. They were always lower than 1.7, 1.9, 2.8, 2.3 and 2.9\% for copper, nickel, iron, calcium and TOC, respectively. The determined values of all the analytes in retentate samples, that cover a wide range of $\mathrm{pH}$ and metals and ligand concentrations, always differed less than $4 \%$ of the expected values. It indicates that the presence of other solutes and the formation and breaking of chelates produces little interference in the analytes determination.

\section{Steady-state experiments without chelating agents}

First, filtrations of metal ions without ligands were tested. Iron filtration was performed separately from the other metals because precipitation was observed above $\mathrm{pH} 3$ and a colored solid accumulated on the membrane surface, which fouled and damaged it. Figure 1 shows the experimental rejections and the fraction of multiply-charged species according to the speciation calculation. Iron rejection is higher than the rejections of the other metals because of the occurrence of trivalent ions. The rejections

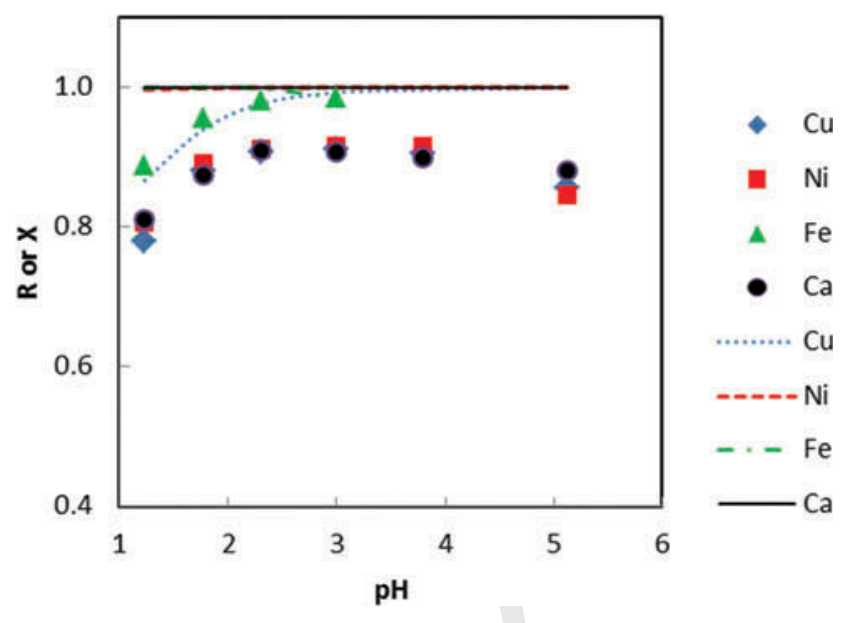

Figure 1. Influence of $\mathrm{pH}$ on metal rejection without chelating agents. Feed: chloride salts, $0.1 \mathrm{mM}$. Symbols: experimental rejection. Lines: fraction of multiply-charged species.

of calcium, copper, and nickel follow similar patterns, reaching a rejection value of 0.91 between $\mathrm{pH}$ values of 2 and 4 . Above $\mathrm{pH} 4$, the rejection of these metals declines due to the decrease in the membrane's positive electrical charge, since the IEP of the membrane is 5-6. ${ }^{[21]}$ At very low $\mathrm{pH}$, the rejections also decrease due to the high ionic strength of the solution and its high $\mathrm{Cl}^{-}$concentration, which screens the positive charge of the membrane. At $\mathrm{pH}$ 1.2 , the rejection of copper (0.78) is slightly lower than that of nickel or calcium (0.81). At this $\mathrm{pH}$, the speciation computations indicate that $13 \%$ of the copper present occurs as the monovalent $\mathrm{CuCl}^{+}$ion, whereas nearly all of the nickel and calcium remain as $\mathrm{Ni}^{2+}$ and $\mathrm{Ca}^{2+}$, respectively. Hydroxide complexes are negligible for calcium, nickel, and copper. However, the acid behavior of $\mathrm{Fe}^{3+}$ yields significant amounts of $\mathrm{FeOH}^{2+}$. The computations give that $\mathrm{FeOH}^{2+}$ represents $46 \%$ and $83 \%$ of the total iron at $\mathrm{pH}$ values of 2.3 and 3.0, respectively. These results agree with the $\mathrm{Fe}^{3+} \mathrm{pK}_{\mathrm{a}}$ values reported in literature, that fall between 2.2 and 3.0 depending on the ionic strenght. ${ }^{[42]}$

\section{Steady-state experiments with EDTA}

For the highest concentration of metals, a solution containing $1 \mathrm{mM}$ of $\mathrm{Cu}^{2+}, \mathrm{Ni}^{2+}$, and $\mathrm{Ca}^{2+}$ and a stoichiometric concentration of EDTA was filtrated. Nearly all of the calcium was rejected (Fig. 2), but experimental rejections of copper, nickel, and EDTA were much lower and increased slightly as the $\mathrm{pH}$ increased. The speciation computations showed that more than $99.8 \%$ of the calcium is present as $\mathrm{Ca}^{2+}$ at all of the experimental conditions. At $\mathrm{pH}$ values of 1.8 and 2.0, nearly all of the nickel and copper are chelated as monovalent 


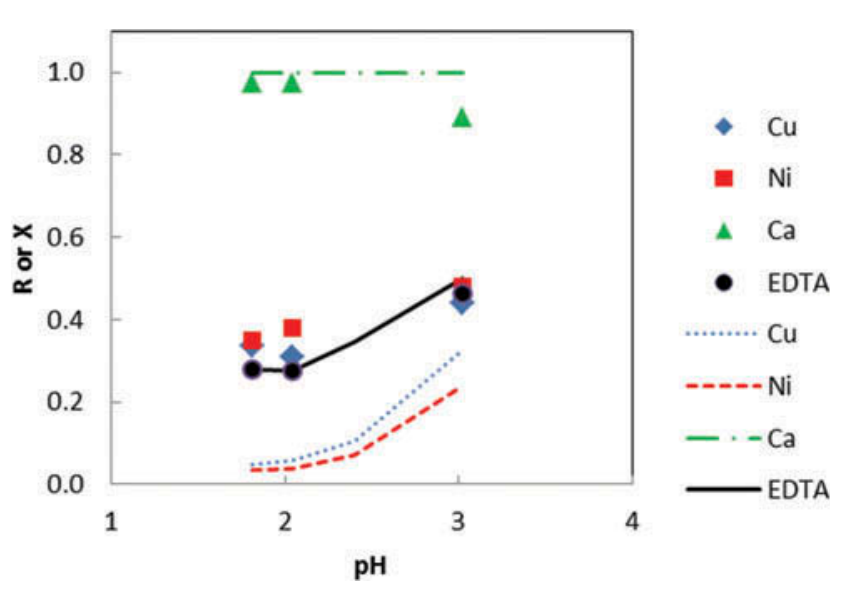

Figure 2. Influence of $\mathrm{pH}$ on rejection. Feed: chloride salts, $1 \mathrm{mM}$; EDTA, $3 \mathrm{mM}$. Symbols: experimental rejection. Lines: fraction of multiply-charged species.

ions $\left(\mathrm{MHEDTA}^{-}\right)$, while divalent ions $\left(\mathrm{M}^{2+}\right.$ and MEDTA $^{2-}$ ) are represented only marginally. The computations also predicted the precipitation of neutral $\mathrm{H}_{4}$ EDTA at $\mathrm{pH} 1.8$ and 2.0, which would not pass through the membrane; however, no solid was observed in the experiments. At $\mathrm{pH}$ 3.0, the presence of MEDTA $^{2-}$ becomes significant and provides a rationale for the increase in rejections of copper, nickel, and EDTA.

Experiments with lower concentrations of metals $(0.1 \mathrm{mM})$ were used to analyze the interference from $\mathrm{Fe}^{3+}$ for the $\mathrm{Cu}^{2+}$ and $\mathrm{Ni}^{2+}$ complexes. All experimental rejections were low and similar, which would make the separation process difficult (Fig. 3). The rejections of iron, showed a minimum at $\mathrm{pH} 1.8$, which increased gradually with increasing $\mathrm{pH}$ from this point and increased more markedly with decreasing $\mathrm{pH}$. The fraction of multiply-

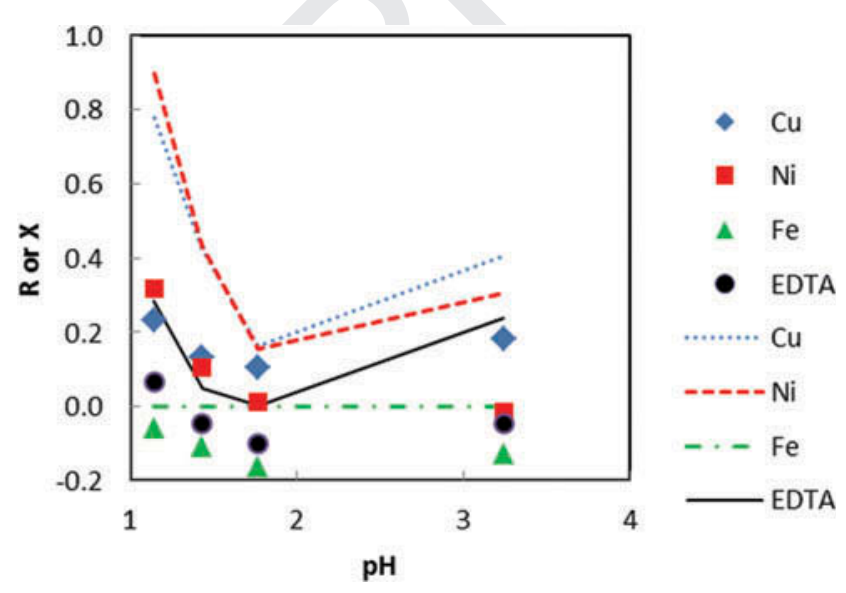

Figure 3. Influence of $\mathrm{pH}$ on rejection. Feed: chloride salts, $0.1 \mathrm{mM}$; EDTA, $0.3 \mathrm{mM}$. Symbols: experimental rejection. Lines: fraction of multiply-charged species.

charges species curves of nickel, copper, and EDTA reproduce this shape, although they overestimate the rejections, particularly for copper and nickel at very acidic conditions.

It should be pointed out that iron and most EDTA rejections were negative. Negative rejections of ions on membrane processes have been reported, explained and modeled. In some cases a negative rejection of an ion is caused by an increase of its concentration along the membrane phase, which is favored by a low electrical potential in the membrane. In electrolyte mixtures, a high concentration of mobile counterions reduces the electrical potential and therefore contributes to the negative rejections of bigger and less mobile counterions. ${ }^{[34,43]}$ Further, the occurrence of negative rejection was explained for slightly charged membranes when Diffusivity coefficients of coions are bigger than those of counterion. ${ }^{[44]}$

The speciation calculation indicates the existence of single charge big counterions such as $\mathrm{ML}^{-}$and a high concentration of both chloride and proton, a more mobile counterion and a very mobile coion, respectively. All these conditions together can lead $\mathrm{ML}^{-}$ions to undergo a negative rejection. At $\mathrm{pH} 1.8$, for instance, $67 \%, 83 \%$, and $85 \%$ of the iron, copper, and nickel were present in the forms of $\mathrm{FeEDTA}^{-}$, $\mathrm{CuHEDTA}^{-}$, and NiHEDTA, respectively, and those species together represented $78 \%$ of the total EDTA content They could lead to the observed negative rejections of iron and EDTA, as their multiply-charged ions are not relevant. In contrast, copper and nickel do not show negative rejections because a significant fraction of them occur as $\mathrm{Cu}^{2+}$ and $\mathrm{Ni}^{2+}$, that are strongly rejected. For instance, at $\mathrm{pH} 1.2$, speciation indicates that $90 \%$ of the nickel and $77 \%$ of the copper had already been released as $\mathrm{Ni}^{2+}$ and $\mathrm{Cu}^{2+}$, respectively. At $\mathrm{pH} 1.8,14 \%$ of them occur as $\mathrm{Ni}^{2+}$ and $\mathrm{Cu}^{2+}$.

\section{Steady-state experiments with citric acid}

Figure 4 shows the rejections of copper, nickel, and calcium and the stoichiometric concentration of citric acid at different $\mathrm{pH}$ levels. The citric acid rejection values are approximately $0.10-0.15$ and change slightly with $\mathrm{pH}$. Conversely, the rejection of the three metals is approximately 0.85 at $\mathrm{pH} 2$. These results indicate a good separation of these metals and the ligand. The low rejection of citric acid was predicted by the computations, which show that species containing this ligand are either neutral (i.e., $\mathrm{H}_{3} \mathrm{Cit}$ and MHCit) or singly charged (i.e., $\mathrm{MH}_{2} \mathrm{Cit}^{+}$and $\mathrm{MCit}^{-}$). The calcium remained free in the form of $\mathrm{Ca}^{2+}$. The copper rejection decreased with increasing $\mathrm{pH}$ because $\mathrm{Cu}^{2+}$ accounts 


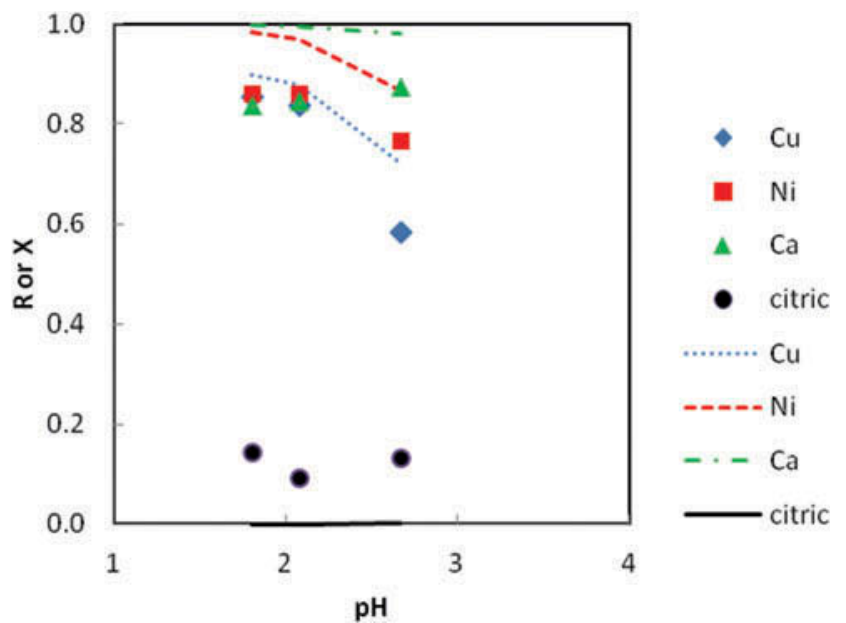

Figure 4. Influence of $\mathrm{pH}$ on rejection. Feed: chloride salts, $1 \mathrm{mM}$; citric acid, $3 \mathrm{mM}$. Symbols: experimental rejection. Lines: fraction of multiply-charged species. for $90 \%$ and $72 \%$ of the copper at $\mathrm{pH}$ values of 1.8 and 2.7, respectively. The remaining copper was in the form of $\mathrm{CuH}_{2} \mathrm{Cit}^{+}$, $\mathrm{CuHCit}, \mathrm{CuCit}^{-}$, or $\mathrm{CuCl}^{+}$. The behavior of nickel was intermediate between those of copper and calcium. The influence of $\mathrm{pH}$ on copper and citric acid rejection agrees with the results observed in a previous study considering only $\mathrm{Cu}^{2+}$ and citric acid. ${ }^{[17]}$

We analyzed the interference from iron competition with copper and nickel through experiments with lower concentrations of metals $(0.1 \mathrm{mM})$. Two ratios of the

395 chelating agent to metals were tested: the stoichiometric ratio and one with 5 times more citric acid. Figures 5 and 6 show that the resulting rejections follow the same tendency in both experiments. Citric acid rejection was low in all of the $\mathrm{pH}$ conditions studied. The iron rejection pattern clearly differs from the rejection of nickel

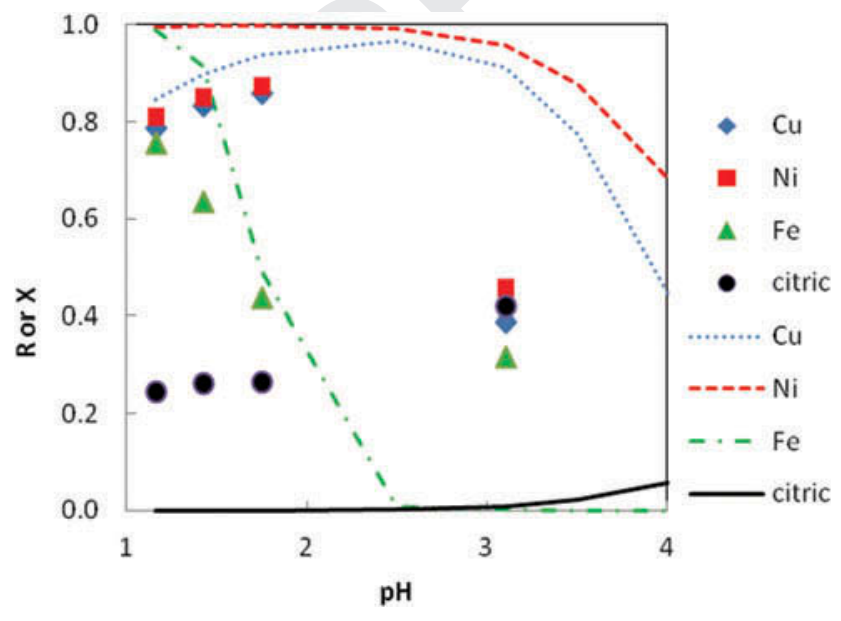

Figure 5. Influence of $\mathrm{pH}$ on rejection. Feed: chloride salts, $0.1 \mathrm{mM}$; citric acid, $0.3 \mathrm{mM}$. Symbols: experimental rejection. Lines: fraction of multiply-charged species.

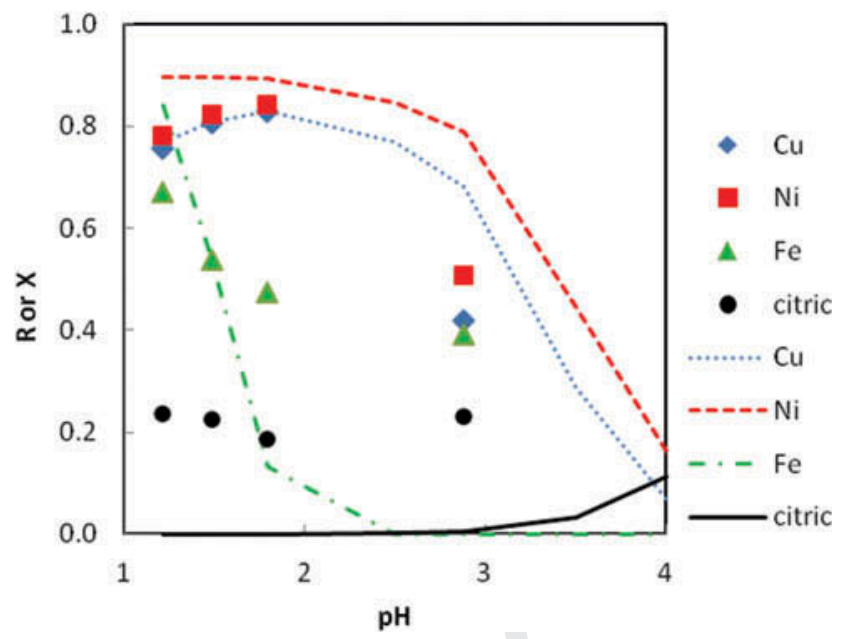

Figure 6. Influence of $\mathrm{pH}$ on rejection. Feed: chloride salts, $0.1 \mathrm{mM}$; citric acid, $1.5 \mathrm{mM}$. Symbols: experimental rejection. Lines: fraction of multiply-charged species.

and copper. Achieving a high rejection of iron requires a $\mathrm{pH}$ of 1.2, whereas copper and nickel can be retained at more moderate $\mathrm{pH}$.

Low citric rejections agree with the speciation computation, which found that multiply-charged citric acid ions (i.e., $\mathrm{Cit}^{3-}$ and $\mathrm{HCit}^{2-}$ ) were negligible and only neutral or singly charged ions (i.e., $\mathrm{H}_{3} \mathrm{Cit}, \mathrm{H}_{2} \mathrm{Cit}^{-}$, FeCit, $\mathrm{CuH}_{2} \mathrm{Cit}^{+}$, CuHCit, CuCit ${ }^{-}, \mathrm{NiH}_{2} \mathrm{Cit}^{+}$, NiHCit, and $\mathrm{NiCit}^{-}$) show high concentrations. The $\mathrm{X}$ curves follow the tendency of the experimental rejections. Nevertheless, the speciation computation predicts that copper and nickel chelates would fragment at higher $\mathrm{pH}$ values than the experimental rejections suggest. Given the high stability of the iron chelates, their fragmentation and subsequent $\mathrm{Fe}^{3+}$ release requires the addition of more acid than the release of $\mathrm{Cu}^{2+}$ and $\mathrm{Ni}^{2+}$. At $\mathrm{pH}$ 1.2, the speciation computation predicted that the iron-citrate chelate is completely fragmented; experimentally, however, the iron rejection is lower than the rejection observed in the absence of ligand, which reduces the separation factor.

\section{Batch filtration with citric acid}

To obtain additional information about the possibility of separating metals from a chelating agent, we carried out a batch concentration experiment. The results of the steady-state experiments showed that it was very difficult to separate EDTA and that interference from iron is more important than interference from calcium. Therefore, a batch concentration experiment was performed using a solution initially containing $\mathrm{Cu}^{2+}, \mathrm{Ni}^{2+}$, $\mathrm{Fe}^{3+}(0.1 \mathrm{mM})$, and citric acid $(1.5 \mathrm{mM})$. The additions of iron and a high concentration of citric acid were 
used to make the conditions for the target separation more demanding. The feed $\mathrm{pH}$ was 1.2 and up to $88 \%$ of the initial volume was filtered. Successive aliquots of the permeate were analyzed, but only a few samples of the retentate were analyzed to avoid disturbing the system.

Throughout the entire process, no significant variation in experimental rejections of any solute was observed. In a batch filtration where the rejection remains constant, the evolution of the retentate concentration is described by Equation 2:

$$
\frac{C}{C_{0}}=\left(\frac{V_{o}}{V}\right)^{R}
$$

where $C$ and $V$ are the retentate concentration and volume, respectively, and $R$ is the presumed rejection. The accumulated permeate concentrations $\left(C_{p}\right)$ can be calculated by Equation 3, as deduced by mass balance:

$$
\frac{C_{P}}{C_{o}}=\frac{\left(\frac{V_{o}}{V}\right)-\left(\frac{V_{o}}{V}\right)^{R}}{\left(\frac{V_{o}}{V}\right)-1}
$$

The instantaneous permeate concentrations $\left(C_{p i}\right)$ can be calculated by Equation 4:

$$
\frac{C_{p i}}{C_{0}}=(1-R)\left(\frac{V_{o}}{V}\right)^{R}
$$

450 Fitting Equation 4 to the experimental results (Fig. 7) yielded the following rejection estimates: 0.76 for nickel, 0.73 for copper, 0.68 for iron, and 0.19 for citric acid. These values are close to those obtained in the steady-state experiment with the same initial condiand 0.24 for citric acid. The calculated evolution of the accumulated permeate concentration is plotted in Fig. 8. After filtering $90 \%$ of the initial volume, the

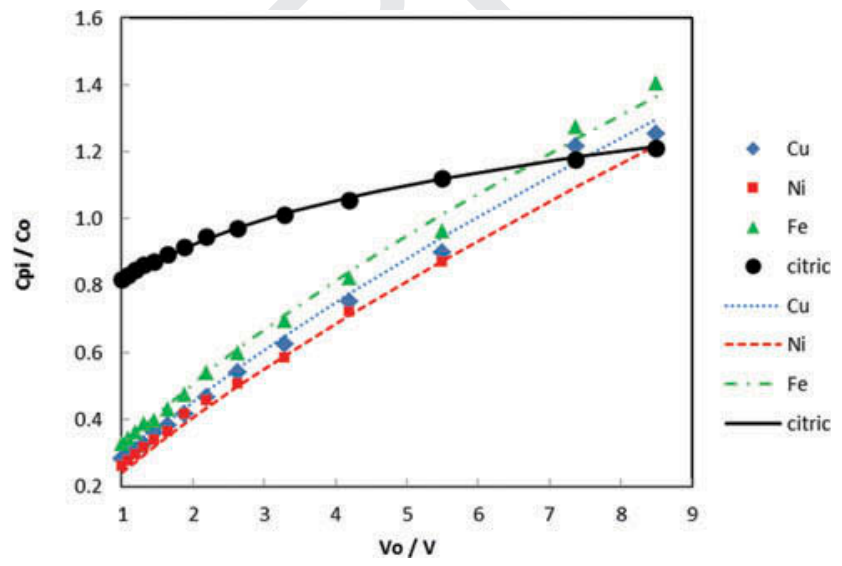

Figure 7. Evolution of instantaneous permeate composition in batch filtration. $\mathrm{pH}=1.2$. Feed: chloride salts, $0.1 \mathrm{mM}$; citric acid, $1.5 \mathrm{mM}$. Symbols: experimental. Lines: calculated.

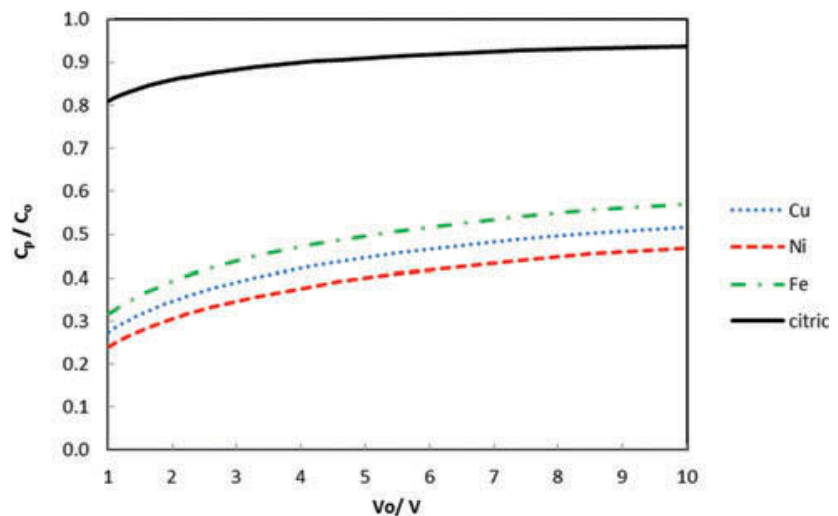

Figure 8. Theoretical evolution of accumulated permeate composition in batch filtration. $\mathrm{pH}=1.2$. Feed: chloride salts, $0.1 \mathrm{mM}$; citric acid, $1.5 \mathrm{mM}$.

accumulated permeate shows a high concentration of citric acid $\left(94 \%\right.$ of $\left.C_{o}\right)$. Although the metal concentrations became lower, they are still significant: $46 \%, 51 \%$, and $56 \%$ of $C_{o}$ for nickel, copper, and iron, respectively. These results indicate that several filtration steps would be necessary to achieve a final permeate with a low metal content and a high citric acid content that can be reused. That is illustrated in the following computations.

Real separations are never absolute. The comparison of the ratio between the concentrations of chelating agent and the metal ion before filtration, $\left(C_{c h} / C_{m}\right)_{o}$, and after filtration in the permeate, $\left(C_{c h} / C_{m}\right)_{p}$, gives an indication of the effectiveness of the real separation. The relationship $\left(C_{c h} / C_{m}\right)_{p} /\left(C_{c h} / C_{m}\right)_{o}$ must be greater than unity and the greater this relationship, the greater the effectiveness of the separation. After doing $\boldsymbol{n}$ successive filtrations, this relationship can be calculated by Equation 5:

$$
\frac{\left(\frac{C_{c h}}{C_{m}}\right)_{p}}{\left(\frac{C_{c h}}{C_{m}}\right)_{o}}=\left(\frac{\left(\frac{V_{o}}{V}\right)-\left(\frac{V_{o}}{V}\right)^{R_{c h}}}{\left(\frac{V_{o}}{V}\right)-\left(\frac{V_{o}}{V}\right)^{R_{m}}}\right)^{n}
$$

where $R_{c h}$ and $R_{m}$ are the rejections of chelating agent and metal ion, respectively. After performing successive filtrations the volume of permeate decreases and can be calculated by Equation 6:

$$
V_{p}=V_{0}\left(1-\frac{1}{\frac{V_{o}}{V}}\right)^{n}
$$

As an example, if $R_{c h}=0.19$ (citric), $R_{m}=0.73$ (copper), and $V_{o} / V=10$, the final volume of permeate will be $90 \%$, $81 \%$, and $73 \%$ of the initial volume for $n=1,2$ and 3 , respectively. The value of $\left(C_{c h} / C_{m}\right)_{p} /\left(C_{c h} / C_{m}\right)_{o}$ will be 1.8 , 3.3 and 5.9, respectively. Then, a final reusable permeate 
with a low metal and a high citric acid content, can be achieved after several filtratrion steps.

\section{Conclusions}

490 In this work, the influence of chemical speciation on the separation of metal ions (i.e., copper, nickel, calcium, and iron) from chelating agents (EDTA and citric acid) by Nanofiltration is evaluated.

A semi-quantitative reproduction of the observed rejection patterns of metals and ligands at different $\mathrm{pH}$ values and concentrations can be drawn assuming that only multiply-charged species are highly rejected. The results reveal that knowledge of chemical speciation is a helpful tool to predict Nanofiltration performance, even though solutions containing numerous solutes are involved in the equilibria of the chemical reactions.

The separation of metal ions from EDTA was poor due to the high chelate stability constants. Separating nickel, copper, and calcium from citric acid was achieved at $\mathrm{pH} \approx 2$, but $\mathrm{pH} \approx 1.2$ is needed for significant iron separation. At $\mathrm{pH} \approx 1.2$, rejections of nickel, copper, iron, and citric acid in batch concentration filtrations were approximately 0.761 , $0.726,0.685$, and 0.191 , respectively. These values are simi-

510 lar to those obtained in the steady-state experiments. In those conditions, speciation calculations indicate an abundance of multiply-charged free metal ions and neutral or singly charged free chelating species.

These results indicate that the separation of multi-

515 ply-charged cations and chelating agents requires a Nanofiltration membrane with low steric hindrance and a high contribution of electrostatic and dielectric interactions. Further, the membrane pore radius should be larger than the species radii, and the membrane 520 should be able to maintain an electric charge in the conditions amenable to chelate fragmentation. Overall, these considerations and results can be used to evaluate the applicability of using Nanofiltration for recycling chelating agents employed to extract heavy metals from contaminated waters or solids.

\section{Acknowledgments}

The authors are grateful to the Ministerio de Ciencia y Tecnología de España (Projects CTQ2005-08346-C02-01/ PPQ) for financial support to conduct this study.

\section{Funding}

This work was supported by the Ministerio de Ciencia y Tecnología de España [CTQ2005-08346-C02-01/PPQ].

\section{References}

[1] Coman, V.; Robotin, B.; Ilea, P. (2013) Nickel recovery/ removal from industrial wastes: A review. Resources, Conservation and Recycling, 73: 229-238. doi:10.1016/j. resconrec.2013.01.019

[2] Kurniawan, T.A.; Chan, G.Y.S.; Lo, W.H.; Babel, S. (2006) Physico-chemical treatment techniques for wastewater laden with heavy metals. Chemical Engineering Journal, 118 (1-2): 83-98. doi:10.1016/j.cej.2006.01.015

[3] Fu, F.; Wang, Q. (2011) Removal of heavy metal ions from wastewaters: A review. Journal of Environmental Management, 92 (3): 407-418. doi:10.1016/j. jenvman.2011.04.005

[4] Saçmaci, Ş.; Kartal, Ş.; Saçmaci, M.; Soykan, C. (2011) Novel solid phase extraction procedure for some trace elements in various samples prior to their determinations by FAAS. Bulletin of the Korean Chemical Society, 32 (2): 444-450. doi:10.5012/bkcs.2011.32.2.444

[5] Yilmaz, V.; Hazer, O.; Kartal, Ş. (2013) Synthesis, characterization and application of a novel ion-imprinted polymer for selective solid phase extraction of copper (II) ions from high salt matrices prior to its determination by FAAS. Talanta, 116: 322-329. doi:10.1016/j. talanta.2013.05.047

[6] Liu, F.; Zhang, G.; Meng, Q.; Zhang, H. (2008) Performance of nanofiltration and reverse osmosis membranes in metal effluent treatment. Chinese Journal of Chemical Engineering, 16 (3): 441-445. doi:10.1016/S1004-9541(08)60102-0

[7] Ku, Y.; Chen, S.-W.; Wang, W.-Y. (2005) Effect of solution composition on the removal of copper ions by nanofiltration. Separation and Purification Technology, 43 (2): 135-142. doi:10.1016/j. seppur.2004.10.011

[8] $\mathrm{Wu}, \mathrm{D}$, et al. (2016) Use of nanofiltration to reject cobalt (II) from ammoniacal solutions involved in absorption of SO2/NOx. Chemical Engineering Science, 145: 97-107. doi:10.1016/j.ces.2016.02.014

[9] Suárez, L.; Diez, M.A.; García, R.; Riera, F.A. (2013) Recovery of Na4EDTA from aqueous solutions using nanofiltration. Separation and Purification Technology, 118: 144-150. doi:10.1016/j.seppur.2013.06.046

[10] Diallo, H.; Rabiller-Baudry, M.; Khaless, K.; Chaufer, B. (2013) On the electrostatic interactions in the transfer mechanisms of iron during nanofiltration in high concentrated phosphoric acid. Journal of Membrane Science, 427: 37-47. doi:10.1016/j.memsci.2012.08.047

[11] Lin, S.; Wang, T.; Juang, R. (2005) Metal rejection by nanofiltration from diluted solutions in the presence of complexing agents. Separation Science and Technology, 39 (2): 363-376. doi:10.1081/SS-120027563

[12] Sorin, A., et al. (2005) Rejection of Gd(III) by nanofiltration assisted by complexation on charged organic membrane: influences of $\mathrm{pH}$, pressure, flux, ionic strength and temperature. Journal of Membrane Science, 267 (1-2): 41-49. doi:10.1016/j. memsci.2005.05.022

[13] Favre-Réguillon, A.; Sorin, A.; Pellet-Rostaing, S.; Bernier, G.; Lemaire, M. (2007) Nanofiltration assisted by complexation: A promising process for the 
separation of trivalent long-lived minor actinides from lanthanides. Comptes Rendus Chimie, 10 (10-11): 9941000. doi:10.1016/j.crci.2007.01.012

[14] Szöke, S.; Pátzay, G.; Weiser, L. (2005) Cobalt(III) EDTA complex removal from aqueous alkaline borate solutions by nanofiltration. 175 (2): 179-185.

[15] Poriel, L.; Chitry, F.; Pellet-Rostaing, S.; Lemaire, M.; Favre-Réguillon, A. (2006) Zirconium and hafnium separation, part 3. Ligand-enhanced separation of zirconium and hafnium from aqueous solution using nanofiltration. Separation Science and Technology, 41 (13): 2883-2893. doi:10.1080/01496390600725810

605

[16] Koseoglu, H.; Kitis, M. (2009) The recovery of silver from mining wastewaters using hybrid cyanidation and high-pressure membrane process. Minerals Engineering, 22 (5): 440-444. doi:10.1016/j. mineng.2008.11.006

[17] Balanyà, T.; Labanda, J.; Llorens, J.; Sabaté, J. (2009) Separation of metal ions and chelating agents by nanofiltration. Journal of Membrane Science, 345 (1-2): 3135. doi:10.1016/j.memsci.2009.08.009

615 [18] Marcus, Y. (1997) Ion Properties, 6th ed.; Marcel Dekker: New York.

[19] Advanced Chemistry Development ACD/ChemSketch. Available at: http://www.acdlabs.com/resources/free ware/chemsketch/. [Accessed May 3, 2018].

620 [20] Koch membrane koch membranes technical information. Available at: http://www.kochmembrane.com/ PDFs/Data-Sheets/Spiral/NF/KMS_SelRO_MPS_36_ 2540_4040_Datasheet.aspx [Accessed October 7, 2016].

[21] Sabaté, J.; Labanda, J.; Llorens, J. (2009) Influence of coion and counterion size on multi-ionic solution nanofiltration. Journal of Membrane Science, 345: 298-304. doi:10.1016/j.memsci.2009.09.013

[22] Bowen, W.R.; Welfoot, J.S.; Williams, P.M. (2002) Linearized transport model for nanofiltration: development and assessment. AIChE Journal. American Institute of Chemical Engineers, 48 (4): 760-773. doi:10.1002/(ISSN)1547-5905

[23] Cavaco Morão, A.I.; Szymczyk, A.; Fievet, P.; Brites Alves, A.M. (2008) Modelling the separation by nanofiltration of a multi-ionic solution relevant to an industrial process. Journal of Membrane Science, 322 (2): 320-330. doi:10.1016/j.memsci.2008.06.003

[24] Déon, S.; Dutournié, P.; Bourseau, P. (2007) Modeling nanofiltration with Nernst-Planck approach and polarization layer. AIChE Journal. American Institute of Chemical Engineers, 53 (8): 1952-1969. doi:10.1002/ aic.v53:8

[25] Déon, S.; Dutournié, P.; Limousy, L.; Bourseau, P. (2011) The two-dimensional pore and polarization transport model to describe mixtures separation by nanofiltration: model validation. AIChE Journal. American Institute of Chemical Engineers, 57 (4): 985995. doi:10.1002/aic.12330

[26] Silva, V., et al. (2011) Multi-ionic nanofiltration of highly concentrated salt mixtures in the seawater range. 277 (1-3): 29-39.

[27] Bandini, S.; Vezzani, D. (2003) Nanofiltration modeling: the role of dielectric exclusion in membrane characterization. Chemical Engineering Science, 58 (15):
[28] Fievet, P., et al. (2002) Electrolyte transport through amphoteric nanoÿltration membranes. 57: 2921-2931.

[29] Palmeri, J., et al. (2002) Modeling of multi-electrolyte transport in charged ceramic and organic nanofilters using the computer simulation program. NanoFlux, 147 (1-3): 231-236.

[30] Lefebvre, X., et al. (2003) Nanofiltration modeling: A comparative study of the salt filtration performance of a charged ceramic membrane and an organic nanofilter using the computer simulation program nanoflux. Separation and Purification Technology, 32 (1-3): 117-126. doi:10.1016/S1383-5866(03) 00076-5

[31] Saliha, B.; Patrick, F.; Anthony, S. (2009) Investigating nanofiltration of multi-ionic solutions using the steric, electric and dielectric exclusion model. Chemical Engineering Science, 64 (17): 3789-3798. doi:10.1016/j. ces.2009.05.020

[32] Pages, N.; Yaroshchuk, A.; Gibert, O.; Cortina, J.L. (2013) Rejection of trace ionic solutes in nanofiltration: influence of aqueous phase composition. Chemical Engineering Science, 104: 1107-1115. doi:10.1016/j. ces.2013.09.042

[33] Wang, K.Y.; Chung, T.S. (2006) Polybenzimidazole nanofiltration hollow fiber for cephalexin separation. AIChE Journal. American Institute of Chemical Engineers, 52 (4): 1363-1377. doi:10.1002/aic.10741

[34] Yaroshchuk, A.E. (2008) Negative rejection of ions in pressure-driven membrane processes. Advances in Colloid and Interface Science, 139 (1-2): 150-173. doi:10.1016/j.cis.2008.01.004

[35] Dermont, G.; Bergeron, M.; Mercier, G.; RicherLaflèche, M. (2008) Soil washing for metal removal: A review of physical/chemical technologies and field applications. Journal of Hazardous Materials, 152 (1): 1-31. doi:10.1016/j.jhazmat.2007.10.043

[36] OLI Systems OLI systems. OLI Studio: stream Analyzer software. Available at: http://www.olisystems.com/. [Accessed October 7, 2016].

[37] Helgeson, H.C.; Kirkham, D.H. (1974) Theoretical prediction of the thermodynamic behavior of aqueous electrolytes at high pressures and temperatures; I, Summary of the thermodynamic/electrostatic properties of the solvent. American Journal of Science, 274 (10): 1089-1198. doi:10.2475/ ajs.274.10.1089

[38] Helgeson, H.C.; Kirkham, D.H. (1974) Theoretical prediction of the thermodynamic behavior of aqueous electrolytes at high pressures and temperatures; II, Debye-Huckel parameters for activity coefficients and relative partial molal properties. American Journal of Science, 274 (10): 1199-1261. doi:10.2475/ ajs.274.10.1199

[39] Helgeson, H.C.; Kirkham, D.H. (1976) Theoretical prediction of the thermodynamic properties of aqueous electrolytes at high pressures and temperatures. III. Equation of state for aqueous species at infinite dilution. American Journal of Science, 276 (10): 97240. doi:10.2475/ajs.276.2.97

[40] Helgeson, H.C.; Kirkham, D.H.; Flowers, G.C. (1981) Theoretical prediction of the thermodynamic behavior of aqueous electrolytes at high pressures and 
temperatures: IV. Calculation of activity coefficients, osmotic coefficients, and apparent molal and standard and relative partial molal properties to $600 \mathrm{oC}$. American Journal of Science, 281 (10): 1249-1516. doi:10.2475/ajs.281.10.1249

[41] Sillen, L.G.; Martell, A.E. (1971) Stability Constants of Metal-Ion Complexes. Special Publication $N^{\circ} 25$, 1st ed.; The Chemical Society: London.

[42] Baes, C.F.J.; Mesmer, R.E. (1976) The Hydrollysis of Cations, 1st ed.; John Wiley and Sons, Inc.: New York.
[43] Bardot, C.; Gaubert, E.; Yaroshchuk, A.E. (1995) Unusual mutual influence of electrolytes during pressure-driven transport of their mixtures across charged porous membranes. Journal of Membrane Science, 103 (1-2): 11-17. doi:10.1016/0376-7388(94)00300-N

[44] Szymczyk, A., et al. (2003) Contribution of convection, diffusion and migration to electrolyte transport through nanofiltration membranes. Advances in Colloid and Interface Science, 103 (1): 77-94. doi:10.1016/S0001-8686 (02)00094-5 